\title{
Hemostasis in Overt and Subclinical Hyperthyroidism
}

\author{
Arash Ordookhani, ${ }^{1}$ and Kenneth D. Burman ${ }^{2, *}$ \\ ${ }^{1}$ Endocrine Section, Department of Internal Medicine, Providence Hospital, Washington, DC, 20017 \\ ${ }^{2}$ Endocrine Section, MedStar Washington Hospital Center, Washington, DC, 20010 \\ "Corresponding author: Kenneth D. Burman, Endocrine Section, MedStar Washington Hospital Center, Washington, DC, 20010, E-mail: kenneth.d.burman@medstar.net
}

Received 2016 November 21; Revised 2017 February 24; Accepted 2017 March 14.

\begin{abstract}
Context: There are contradictory results on the effect of hyperthyroidism on hemostasis. Inadequate population-based studies limited their clinical implications, mainly on the risk of venous thromboembolism (VTE). The present review focuses on hemostatic changes in overt and subclinical hyperthyroidism.

Methods: A systematic literature search was conducted employing MEDLINE database. The following words were used for the search: Hyperthyroidism; thyrotoxicosis; Graves disease; goiter, nodular; hemostasis; blood coagulation factors; blood coagulation disorders; venous thromboembolism; bleeding; fibrinolysis. The articles that were related to hyperthyroidism and hemostasis are used in this manuscript.

Results: Hyperthyroidism, either overt or subclinical, renders a hypercoagulable state, although there are several studies with contradictory findings in the literature. Hypercoagulability may be caused by an increase in the level of various coagulation factors such as factor (F) VIII, FX, FIX, von Willebrand $\mathrm{F}(\mathrm{vWF})$, and fibrinogen, while hypofibrinolysis by changes in coagulation parameters such as a decrease in plasmin and plasmin activator or an increase in $\alpha 2$-antiplasmin, plasminogen activator inhibitor-1 and thrombin activatable fibrinolysis inhibitor

Conclusions: Although many reports are in favor of a hypercoagulable state in overt hyperthyroidism but this finding at the biochemical level and its clinical implication, on the occurrence of VTE, has yet to be confirmed.
\end{abstract}

Keywords: Hyperthyroidism, Hypothyroidism, Thyroiditis, Autoimmune, Hashimoto Disease, Myxedema, Venous Thromboembolism, Blood Coagulation Factors, Fibrinolysis, Thyroid Neoplasms

\section{Context}

Hemostasis is an essential process that maintains the integrity of the blood stream in the human body. This process is achieved through a balance between hemostatic plug formation (primary hemostasis) and thrombin generation (secondary hemostasis) in one hand, and fibrinolytic system, on the other hand, to maintain vascular patency (1-6). Disequilibrium between activators and inhibitors of the hemostatic system may result in bleeding or pathological thrombosis. Tendency to thrombosis, arterial and/or venous, is associated with increased morbidity and mortality $(1,2,7)$.

Thyroid hormones are potent mediators of numerous physiological processes and their abnormalities can adversely affect various steps in the coagulation cascade (811). The earliest reports on a link between thyroid disorders and coagulation abnormalities are from the early years of the past century (12-14). Thyroid dysfunction has been associated with contradictory findings on coagulation abnormalities, ranging from subclinical laboratory derangements to clinical bleeding and thromboembolism (15-25). The present report provides a review on hemostatic alteration in hyperthyroidism.

\section{Methods}

A comprehensive review of the literature has been done and the following search terms (medical subject heading, terms, and text words) were used for the MEDLINE search until March 2016: Hyperthyroidism; thyrotoxicosis; Graves disease; goiter, nodular; hemostasis; thyroid hormones; blood coagulation factors; blood coagulation tests; blood coagulation factors; blood coagulation disorders; venous thromboembolism; bleeding; fibrinolysis; receptors thyroid hormone; hemostasis; thyroiditis, autoimmune. In addition, by hand-searching reference lists in review articles and relevant textbook chapters were searched for papers beyond 2000. The eligibility criteria were inclusion of all types of studies that evaluated alterations in hemostatic parameters and/or occurrence of clinical hemostatic events including venous thromboembolism (VTE) and/or bleeding in any type of hyperthyroidism. The authors reviewed all the titles and abstracts generated by the search engine and exclude those that were not covering the eligibility criteria. For potentially relevant studies hard copies of the full article was obtained and the studies were reviewed in detail to make sure they met the inclusion criteria. Figure 1 shows the flowchart of studies assessed and selected by two reviewers. A total of 878 papers were cited and after exclusion 637 papers that did not meet inclusion criteria, 241 papers were thoroughly studied and in order to submit the current manuscript to this jour- 
nal, the number of papers was further decreased (Figure 1). In order to prevent missing any scientific points from the omitted papers, review articles containing those scientific points were used in the manuscript's reference list. Throughout the manuscript, evidence in favor of hypercoagulability, hypocoagulability, or no alterations in hemostatic parameters, if applicable, has been provided.

Studies retrieved in the primary search $(n=878)$

Studies not meeting aim of the review $(n=637)$

Articles reviewed thoroughly by the authors $(\mathrm{n}=241)$

Articles selected to be used in the review $(n=96)$

Figure 1. Flowchart of Assessment and Selection of the Studies Used in This Review

\section{Results}

\subsection{Overt Hyperthyroidism}

Hyperthyroidism is found in $1.3 \%$ of the U.S. population of which $0.5 \%$ is clinical- and $0.7 \%$ subclinical hyperthyroidism (26)

\subsubsection{Hypercoagulability}

The initial reports regarding thyroid and coagulation disorders were in 1913 and 1927 reporting an association between thyrotoxicosis and cerebral venous thrombosis (1214). Several case reports described individuals with hyperthyroidism and cerebral venous thrombosis (27-31). Subsequent studies evaluated thyroid dysfunctions in relationship to alterations in coagulation-fibrinolytic system. Most reports supported a hypercoagulable state and hypofibrinolysis in hyperthyroidism (32-34).

Patients with hyperthyroidism display a tendency to develop thromboembolic complications, with major embolism accounting for up to $18 \%$ of deaths in patients dying from thyrotoxicosis $(35,36)$. The incidence of arterial thromboembolism in patients with atrial fibrillation is higher in those with hyperthyroidism than non-thyrotoxic individuals (37).

Hyperthyroidism and an excess of thyroid hormones are associated with a hypercoagulable state $(9,32)$ and these has led to the hypothesis that hyperthyroidism maybe considered a risk factor for venous thromboembolism. Confirmation of this association may change clinical practice as for decision whether venous thromboembolism (VTE) in a hyperthyroid patient would be considered provoked or unprovoked. Some authors assert that hyperthyroidism as a risk for VTE (38).

Increased and reduced risks of VTE have been associated with high and low levels of free T4, respectively (39). In a recent case report, the authors presented two patients with severe VTE with hyperthyroidism and no other risk factor for VTE, emphasizing possible association between hyperthyroidism and VTE (40). However, studies on the effect of elevated free T4 on the occurrence of VTE are scarce and there has been controversy over whether thyroid hormone excess leads to an increased risk of thrombosis (4143). Recent large-scale studies have shown an association between VTE and high free T4 levels. Following age- and sex-adjustment, Free T4 levels above $17 \mathrm{pmol} / \mathrm{L}$ resulted in an odds ratio (OR) and $95 \%$ confidence interval (95\% CI) of 2.2 (95\% CI, 1.2 - 4.2) for DVT. This further increased up to an OR of 13.0 (95\% confidence interval (CI), 1.1 - 154.1) for free T4 levels above reference range. The authors suggest increasing levels of free T4 to be a risk factor for VTE (39). The HUNT2 cohort study in Norway, showed that there is a $\sim 10$ fold increased risk of occurrence of VTE for free T4 levels $>$ 17.3 pmol/L(i.e., above 98 th percentile) after adjustment for age, sex, and body mass index. The authors concluded that free $\mathrm{T} 4$ levels at higher end of normal range are strong risk factor for VTE (44). In a nation-wide longitudinal study for 5 years including 8,903 individuals with hyperthyroidism as a study cohort and 44,515 individuals without hyperthyroidism as the comparison controls, there was a 2.31 times greater risk (95\% CI, $1.20-4.45, \mathrm{P}=0.012$ ) of pulmonary embolism (PE) in patients with hyperthyroidism than in the comparison cohort (45). In the MEGA study, which is a large population-based case-control study, 2,177 individuals with DVT and/or PE were recruited as cases as well as 2,826 age- and sex-matched individuals as controls. Increases in mean levels of FVIII, FIX, fibrinogen, and vWF were observed with increasing levels of free $\mathrm{T} 4$ among the controls, which showed that high free T4 values were associated with increased levels of prothrombotic factors. Additionally, there was an association between free T4 levels and both DVT and PE. For levels of free T4 > 24.4, pmol/L, the OR (95\% CI) for DVT was 2.7 (95\% CI, 1.2 - 6.1) and for levels of free T4 of $22.2 \mathrm{pmol} / \mathrm{L}$, the OR (95\% CI) for PE was 2.5 (1.2 - 5.1). It was concluded that high free $\mathrm{T} 4$ values increase 
the risk of VTE by increasing the concentration of circulating FVIII, FIX, fibrinogen, and vWF (46). A retrospective cohort study including 587 hyperthyroid patients and diagnosis of VTE within 6 months before or after diagnosis of hyperthyroidism was conducted in the Netherlands. The study revealed an incidence rate of 8.7 (95\% CI 2.8 - 20.2) per 1,000 person-years. Three of these five patients had a first VTE, giving an incidence rate of 5.3 (95\% CI 1.1-15.6) per 1,000 person-years for first VTE. In the general population, the incidence rate for first VTE is between 0.6 - 1.6 and for all VTE is between 0.7 - 1.8 per 1,000 person-years. Therefore, the incidence of VTE in patients with hyperthyroidism is higher than the general population (47). In a large-scale retrospective cohort study, databases of linked statistical records of hospital admissions and death certificates for the Oxford record linkage study area (ORLS1:1968 to 1998 and ORLS2:1999 to 2008) and the whole of England (1999 to 2008) were analyzed. Rate ratios for VTE were determined, comparing immune-mediated disease cohorts with comparison cohorts. Significantly but mildly elevated risk for VTE was found in thyrotoxicosis in ORLS2 population with a rate ratio of 1.56 (95\% CI, $1.23-1.95, \mathrm{P}<0.001)$ and in the England data set with a rate ratio of 1.34 (95\%CI, 1.27-1.42, $\mathrm{P}<0.001$ ), but not in ORLS1 population. Systemic lupus erythematous showed the highest risk ratio among several immune-mediated disorders in the study (48).

Qualitative and quantitative platelet abnormalities have been reported in patients with hyperthyroidism (4953); however, there are studies where no significant change in platelet count has been observed in hyperthyroid patients compared to controls (50). A study on parameters of primary hemostasis in both hypo- and hyperthyroid patients showed that hyperthyroid patients had normal bleeding time, although agglutination induced by ristocetin as marginally reduced. Template bleeding time was significantly increased during treatment but remained within normal range and no significant change occurred in platelet agglutination or aggregation due to treatment (51).

The large cross sectional Study of Health in Pomerania in Germany showed higher plasma fibrinogen in overt hyperthyroidism (mean TSH of $0.04 \mathrm{mU} / \mathrm{L}$ and elevated free T4) compared to euthyroids (mean TSH of 0.82 and normal free T4). This is in support of a procoagulant effect in hyperthyroidism (54).

Significant decrease in PT and aPTT and elevation in levels of fibrinogen have been observed in hyperthyroidism, which is in favor of a hypercoagulable state (50). Shortened aPTT was observed in hyperthyroidism in a study on a general population of unselected outpatients (55). Hyperthyroidism renders a hypercoagulable and hypofibrinolysis states $(32,34,49)$ and is associated with significantly increased fibrinogen (that may promote hypercoagulability), decreased plasminogen and plasminogen activator, and non-significant changes in PAI and antiplasmin levels (56), increased levels of FVIII, vWF, and fibrinogen (18, $19,32,57)$, increased vWF activity and fibrinogen levels (18, $58,59)$, and decreased t-PA levels (18). Elevated plasma levels of FVIII, FIX, vWF, and fibrinogen and increased PAI-1 (that decreases fibrinolysis) have been reported in hyperthyroidism and in healthy individual taking thyroid hormones $(18,32,54,55,60-62)$. Increased plasma levels of fibrinogen and fibrinopeptide $\mathrm{B} \beta 15$ - 42, a specific product of fibrinogen metabolism induced by plasmin, were observed in hyperthyroid patients. The restoration of euthyroidism either by antithyroid drug or by radioiodine caused a significant decrease of fibrinogen and $\beta$ beta 15 - 42 (22). However, the majority of these studies methodological limitations and deduction of a net effect of excess thyroid hormone on heamostatic system remains to be clarified (32). Using medium quality observational studies in a meta-analysis revealed significant decrease in bleeding time and plasminogen, increase in $\alpha-2$ antiplasmin (and therefore, a possible increase in inactivation of plasmin), no difference in prothrombin fragment 1 - 2 and ristocetin agglutination and tissue plasminogen activator activity and plasmin-antiplasmin complex. Levels of vWF antigen, fibrinogen, tissue plasminogen activator antigen (tPA:Ag), and plasminogen activator inhibitor 1(PAI-1) were reported as increased or unchanged in different studies (32).

Hyperthyroidism-induced vWF elevation is associated with enhanced platelet function and therefore shortened collagen-epinephrine-induced closure time (CEPI-CT) values. These changes may contribute to the higher risk for cardiovascular disease in patients with hyperthyroidism (63). Platelet plug formation decreases during therapy with thiamazole (57).

In a case-control study, including 42 Graves' disease and 75 toxic nodular goiter as the hyperthyroid group versus 39 healthy controls, circulating markers of endothelial dysfunction, including interleukin (IL) -6, IL-12, IL-18, fibrinogen, plasminogen activator inhibitor 1 (PAI-1), vWF, and vascular cell adhesion molecule-1 (sVCAM-1) were significantly elevated in the patients with both overt hyperthyroidism and subclinical hyperthyroidism. The results suggest that both overt- and subclinical hyperthyroidism may be associated with endothelial dysfunction, which is reflected by decreased fibrinolytic activity, hypercoagulability, and increased levels of IL-6, IL-12, and IL-18 and depends not only on the cause but also on the degree of hyperthyroidism (64). Plasma PAI-1 activity, but not adipose tissue secretion of PAI-1, was increased in hyperthyroid Graves' disease before treatment as compared to dur- 
ing anti-thyroid treatment $(\mathrm{P}=0.01)$ and to euthyroid controls $(\mathrm{P}=0.0001)$. Hyperthyroidism is associated with the formation of a compact fibrin network ex vivo, which are resistant to fibrinolysis (65), representing one plausible mechanism explaining increased risk of thrombosis in hyperthyroid patients (66). Secretion of IL-6 by adipose tissue was increased in hyperthyroid state both before and during anti-thyroid treatment compared to controls, which suggests thyroid autoimmune pathology may regulate secretion of IL-6 from adipose tissue (67).

In hyperthyroid patients the plasma concentrations of AVP and endothelium-associated proteins (EAP) were significantly higher than in the control group. Rendering hyperthyroid patients into the euthyroid state significantly lowered AVP, fibronectin, and vWF compared with pretreatment levels (61).

Hyperthyroid patients with Graves' disease showed significantly elevated levels of plasma thrombomodulin and vWF antigen, which both are synthesized by endothelial cells and are known as markers of endothelial injury. By normalization of thyroid function, the increased levels returned to normal $(58,68,69)$.

Iatrogenic hyperthyroidism in a patient with extremely high single dose $(25 \mathrm{mg}$ ) of levothyroxine ingestion following a suicidal attempt showed increased levels of FVIII, FIX, FX, von Willebrand factor ristocetin cofactor activity (VWF:RiCo), von Willebrand factor antigen (vWF:Ag), plasminogen activator inhibitor 1 (PAI-1), and endogenous thrombin potential. No clear change was observed in FII, FVII, PT, aPTT, protein C activity, total and free protein $\mathrm{S}$ antigen, and prothrombin fragment. The findings suggest that thyroid hormone excess shifts the hemostasis balance towards a hypercoagulable and hypofibrinolysis state, increasing the risk of VTE (70). T3 upregulated coagulation factor genes resulting in T3induction ratios of 8-fold for thrombin, 4.9-fold for FX, and 2- to 3-fold for fibrinogen transcription (11).

Both elevated and low TAFI antigen levels have been reported for hyperthyroid patients $(71,72)$. Elevated TAFI has been detected in several studies on hyperthyroidism. Increased TAFI and decreased $\mathrm{FV}$, protein $\mathrm{C}$, protein $\mathrm{S}$, and tissue factor pathway inhibitor (TFPI) in hyperthyroid patients represent a potential hypercoagulable and hypofibrinolytic state, which might augment the risk for atherosclerotic and atherothrombotic complications (72). The changes in hemostatic parameters in favor of a hypercoagulable state in overt hyperthyroidism are summarized in Table 1.

\subsubsection{Hypocoagulability or No Alterations in Hemostasis}

There are some studies that are inconsistent with enhanced hypercoagulability in hyperthyroidism. In a large- scale study from the national hospital discharge survey (NHDS) databank for the patients being discharged from the hospital, hyperthyroidism was not associated with an increased risk of VTE (relative risk $=0.98,95 \% \mathrm{CI}=0.96-1.01$ ) (43). A recent meta-analysis has shown under-reporting of thromboembolic events in clinical trials (73). Although the study on lack of association of hyperthyroidism and VTE is not a meta-analysis (43), however, there is a potential that this under-reporting would also be present among their VTE cases (43), and therefore, become the source of error in the results and their interpretation. Limitations related to VTE identification and classification, the underlying cancer, and to management process, such as inadequate documentation may result in this underestimation (74).

Development of Graves' disease in a patient with chronic Hashimoto's thyroiditis was accompanied with a hemorrhagic disorder with bleeding into muscle, joints, and skin, secondary to an acquired FVIII deficiency due to a factor VIII inhibitor (75). A severe hemorrhagic disorder due to factor VIIIc antibody, in a patient with hyperthyroid Graves' disease not associated to overt clinical features was reported (76).

In a study, half of Graves' disease individuals, however, had low platelet count and shortened platelet survival that returned to normal levels after antithyroid treatment (52). The platelet changes observed in hyperthyroidism, such as lower platelet count and increased mean platelet volume in conjunction with a shortened platelet lifespan reflect metabolically rather than immunologically mediated phenomena (53).

On the contrary to abovementioned reports (72), low TAFI antigen levels have been reported in overt hyperthyroidism (71). Apparently, this is in favor of a hypocoagulable state as TAFI attenuates fibrinolysis. However, authors found PAI-1 was elevated as well. The inverse correlation of two inhibitors of fibrinolytic system is a complex condition, and therefore, the authors assumed that this low TAFI antigen level might be due to activation of TAFI pathway (71). Levothyroxine suppression therapy in premenopausal women with benign thyroid nodules resulted in non-significant decrease in TAFI antigen and increase in PAI-1 antigen levels (77).

Hyperthyroidism has increased metabolic clearance of FII, FVIII, FIX, and FX and lowered activity of FII (78). Decreased levels of FX (18) and increased levels of antithrombin III have been reported earlier, although the latter has not been attributed to a bleeding tendency (18). Warfarin produced a greater fall in FII and FVII and a greater increase in prothrombin ratio and partial thromboplastin time with kaolin in the hyperthyroid state than in the euthyroid state $(79,80)$.

Plasminogen activators of tissue-(t-PA) and urokinase- 
Table 1. Summary of Attributed to Hypercoagulability in Overt Hyperthyroidism ${ }^{\text {a }}$

\begin{tabular}{|c|c|}
\hline Changes in Hemostatic Parameters & References \\
\hline Increased level of fibrinogen, FVIII, FIX, FX, vWF \& vWF Ag, PAI-1 and vWF:C, FVIII:C, vWF:RCo & $(18,19,32,46,50,54-62,64,70)$ \\
\hline \multicolumn{2}{|c|}{$\begin{array}{l}\text { Increased IL-6, IL-12, IL-18, and sVCAM-1 and fibrinogen and PAI-1 (indicating endothelial dysfunction predisposing a } \\
\text { decreased fibrinolytic activity and hypercoagulability) }\end{array}$} \\
\hline Increased fibrinopeptide $B$ $\beta 15$ - 42 and fibrinopeptide $A$ & $(22,32)$ \\
\hline Increased plasma thrombomodulin & $(57,68,69)$ \\
\hline Increased $\alpha 2$-antiplasmin & $(32)$ \\
\hline Increased TAFI & $(72)$ \\
\hline Increased formation of compact fibrin ex vivo resistant to fibrinolysis & $(65)$ \\
\hline \multicolumn{2}{|l|}{ Decrease in CEPI/CT reflecting enhanced PLT function } \\
\hline Decrease in FV and protein $C$ and protein $S$ and TFPI & $(72)$ \\
\hline Decrease in PT and aPTT & (50) \\
\hline Decreased plasminogen & $(32,56)$ \\
\hline Decreased plasminogen activator [t-PA] & $(56)$ \\
\hline
\end{tabular}

(u-PA) type are known to be potent stimulators of plasmin formation in blood plasma. The fibrinolytic system is activated when t-PA transforms plasminogen to plasmin. Plasmin is a very strong proteolytic enzyme, which can digest not only fibrin if it is present in the vessel system but also other proteins such as coagulation factors. Only free t-PA has fibrinolytic activity and is inhibited when PAI-1 and other inhibitors form an enzymatically inactive complex with t-PA. PAI, such as PAI-1, is a strong inhibitor of fibrinolytic activation (81). Plasma concentrations of t-PA, $\mathrm{u}$ PA and PAI-1 were significantly higher in 33 hyperthyroid Grave's cases than 33 controls. Interpretation of the results is difficult and the authors assumed that prothrombotic effect of PAI-1 elevation was in response to the hypocoagulation effect of elevated t-PA and u-PA (82).

Tissue factor pathway inhibitor (TFPI) is a vascular anticoagulant, which inhibits the initial reaction of the tissue factor-mediated coagulation pathway. It dampens the initiation of blood coagulation by inhibiting two potent procoagulant complexes, tissue factor-factor VIIa (TF-FVIIa) and early forms of prothrombinase. Alternative splicing of mRNA produces two TFPI isoforms, TFPI $\alpha$ and TFPI $\beta$. Both isoforms inhibit TF-FVIIa, but only TFPI $\alpha$ can inhibit early forms of prothrombinase. TFPI $\alpha$ and TFPI $\beta$ are produced in cultured human endothelial cells. Some portion is constantly released into plasma as free form and some binds to lipoprotein particles. Pharmaceutical agents have been developed that block TFPI function to treat hemophilia (83).
In a study of 15 patients with hyperthyroidism and Graves' disease, 10 patients with anti-thyroid medication-induced euthyroidism and Graves' disease, and 25 controls, plasma levels of total TFPI and free TFPI were significantly higher in hyperthyroid Grave's patients compared to euthyroid Graves' and controls. This appears to be in favor of a hypocoagulation state. Free TFPI was similar between Euthyroid Grave's and controls. Plasma free TFPI levels correlates closely with free T3 levels, which suggests that thyroid hormones might influence synthesis and metabolism of TFPI. No relationship was found between plasma free TFPI and thyroid autoantibodies and therefore, it was assumed that autoimmune component of Graves' disease had no effect on plasma free TFPI levels (68).

Hyperthyroidism has been reported to be associated with no change from normal in clotting factors II, V, IX, and $\mathrm{X}(84)$.

For hyperthyroidism and its effect on coagulation system proposed mechanisms are, but not limited to, direct and indirect effects of thyroid hormone excess and autoimmunity. In a study on 35 non-smoking, postmenopausal women, aged 51 - 69, with subclinical or overt hyperthyroidism elevated fibrinogen and D-dimers levels were observed in hyperthyroid subjects. There was a negative correlation between plasma fibrinogen and D-dimers levels and anti-thyroid perioxidase antibodies (TPOAb) levels. The changes in fibrinogen and D-dimer levels were reversible as they decreased after radioiodine therapy. The 
authors assumed that this reversal might relate to the severity of hyperfunctioning and autoimmunity of thyroid disorder. The findings are supportive for hypercoagulation and hyperfibrinolysis states (85). In summary, several changes in coagulation factors are supportive of a prothrombotic state in subclinical hyperthyroidism $(18,32,34$, $49,54,57,59,86)$ and are summarized in Table 2.

\subsection{Subclinical Hyperthyroidism}

National health and nutrition examination survey (NHANES III) showed subclinical hyperthyroidism in $0.7 \%$ of the U.S. population (26).

\subsubsection{Hypercoagulability}

Subclinical hyperthyroidism, which is defined as low TSH and normal freeT4 and T3 is typically caused by the similar conditions that result in overt hyperthyroidism. The clinical implications of subclinical hyperthyroidism have been reviewed elsewhere (87). Undesirable effects of the subclinical hyperthyroidism on cardiovascular system are not different whether its etiology is endogenous or exogenous (88). However, the association between subclinical hyperthyroidism and cardiovascular morbidity and mortality is controversial (89-92). Studies on subclinical hyperthyroidism and hemostasis-fibrinolytic system are scarce $(10,93)$.

A large cross sectional Study of Health in Pomerania in Germany showed higher plasma fibrinogen in subclinical hyperthyroidism (mean TSH of $0.2 \mathrm{mU} / \mathrm{L}$ and normal free T4) versus euthyroids (mean TSH of 0.82 and normal free T4). This is in favor of a potentially prothrombotic state. TSH was an independent risk factor for elevated levels of plasma fibrinogen (54).

A meta-analysis on observational studies with medium-quality scores revealed significantly increased $\mathrm{vWF}: \mathrm{C}$ and fibrinogen levels. A hypercoagulable state is considered to be present in subclinical hyperthyroidism $(32,49)$. Increased factor $X$ activity in patients with subclinical hyperthyroidism represents a potential hypercoagulable state, which might augment the already existing risk for atheroscleroic complications (86). Numerous clinical and experimental studies suggest that elevated vWF levels reflect endothelial dysfunction or damage. A study on 20 subclinical hyperthyroid versus 20 euthyroid subjects showed significantly higher levels of vWF in subclinical hyperthyroid individuals (94). This could contribute to an increase in the risk of cardiovascular events in subclinical hyperthyroidism.

A study on iatrogenic (thyroidectomy- and radioiodine-induced) hypothyroidism compared to iatrogenic (thyroxine-induced) subclinical hyperthyroidism on the same patients revealed that $\mathrm{vWF}$ and fibrinogen were significantly higher in the latter, though vWF was still within normal range and fibrinogen exceeded slightly above the normal limit (25). This is in support of a tendency toward a prothrombotic status in subclinical hyperthyroidism (95). Another study was conducted on 90 thyroidectomized patients (due to differentiated thyroid cancer), followed by radioactive iodine treatment for remnant ablation, was conducted. Multiple hemostatic parameters in severe hypothyroidism versus subclinical (mild) hyperthyroidism (suppressed TSH and normal free $\mathrm{T} 4$ and free $\mathrm{T} 3$ ) were checked before and after levothyroxine suppression treatment. To prevent any effect of residual disease, those with measurable serum thyroglobuin or anti-thyroglobulin antobodies were excluded. Subclinical hyperthyroidism was associated with a hypercoagulable/hypofibrinolytic state and alteration of primary hemostasis toward prothrombotic state. These were reflected by a significant increased in plasma levels of PAI-1, FVIII, vWF antigen, fibrinogen, and antithrombin and a significant reduction in closure time with collagen/epinephrine (CEPI-CT), in closure time with collagen/ADP in platelet function analyzer (PFA-100), a levels of prothrombin fragment $1+2$. Tissue plasminogen activator antigen was similar between two groups (63).

Subclinical hyperthyroidism was associated with significantly increased interleukin (IL) -6, IL-12, plasminogen activator inhibitor 1 (PAI-1), and vascular cell adhesion molecule-1 (sVCAM-1) compared to controls. However, levels of fibrinogen, vWF, and IL-18 were similar. The authors assumed that the results may suggest that subclinical hyperthyroidism may be associated with endothelial dysfunction, which is reflected by decreased fibrinolytic activity, hypercoagulability, and increased levels of IL-6, IL12 , and depends not only on the cause but also on the degree of hyperthyroidism, as overt hyperthyroid patients showed higher levels of markers of endothelial dysfunction compared to the subclinical hyperthyroid cases (64).

Elevated fibrinogen is an independent risk factor for cerebrovascular disorders and elevated D-dimer levels have been associated them as well. In 36 subclinical hyperthyroid- and 36 euthyroid control subjects matched for age, gender, and body mass index, fibrinogen and Ddimer levels were significantly higher in the subclinical hyperthyroidic- than in the euthyroid group, suggesting a relatively hypercoagulable state in subclinical hyperthyroidism (96). The changes in hemostatic parameters in favor of a hypercoagulable state in subclinical hyperthyroidism are summarized in Table 3.

\subsubsection{Hypocoagulability or No Alteration in Hemostasis}

Subclinical hyperthyroid patients showed lower TAFI antigen levels compared to the controls, which is in fa- 
Table 2. Summary of in Favor of Hypocoagulability in Overt Hyperthyroidism

\begin{tabular}{|c|c|}
\hline Changes in Hemostatic Parameters & References \\
\hline Increased FVIII inhibitor causing acquired FVIII deficiency & $(75,76)$ \\
\hline Increased metabolic clearance of FII, FVIII, FIX, FX & (78) \\
\hline Increased plasma t-PA and u-PA & $(82)$ \\
\hline Increased total and free TFPI & (68) \\
\hline Increased mean PLT volume & $(53)$ \\
\hline Decreased PLT count & $(49,52,53)$ \\
\hline Decreased (shortened) PLT survival (life span) that returned to normal levels after antithyroid treatment & $(49,52,53)$ \\
\hline Decreased TAFI Ag & (71) \\
\hline Decreased FII:C & (78) \\
\hline Decreased FX & $(18)$ \\
\hline
\end{tabular}

Table 3. Summary of Attributed to Hyper- and Hypocoagulability in Subclinical Hyperthyroidism ${ }^{\mathrm{a}}$

\begin{tabular}{|c|c|}
\hline Changes in Hemostatic Parameters & References \\
\hline \multicolumn{2}{|l|}{ Hypercoagulability } \\
\hline Increased level of fibrinogen & $(25,32,54,63,96)$ \\
\hline Increased vWF:C & $(32,49)$ \\
\hline Increased FX:C & $(86)$ \\
\hline Increased level of vWF (vWF Ag) and FVIII & $(25,63,94,95)$ \\
\hline Increased IL-6, IL-12, PAI-1, and sVCAM-1 reflecting endothelial dysfunction rendering a hypercoagulable state & $(64)$ \\
\hline $\begin{array}{l}\text { Decrease in closure time with collagen/epinephrine (CEPI/CT) and Collagen/ADP in pletelet function analyzer [PFA-100], reflecting } \\
\text { enhanced PLT function Hypocoagulability }\end{array}$ & $(63)$ \\
\hline Decreased TAFI Ag & $(71)$ \\
\hline
\end{tabular}

vor of hypocoagulation. Although the TAFI levels were not quite statistically significant $(\mathrm{P}=0.508)$, their levels were similar to overt hyperthyroidism and, additionally, there were low number of cases assessed in the study. On the other hand, PAI-1 levels were elevated as well. As both PAI1 and TAFI are inhibitors of fibrinolytic system, a reverse correlation between two inhibitors is a complex situation. The authors assume that this might be a reflection of an activation of TAFI pathway (71). In a study in Sudan, PT, aPTT, fibrinogen, and platelet counts were not different in subclinical- and overt hyperthyroidism (50). In general, the studies on subclinical hyperthyroidism and hemostasis are scarce and current findings are more in favor of a hypercoagulable state. More studies are required in this regard (see Table 3).

\section{Conclusions}

Although most of the studies are in favor a hypercoagulable state in both overt- and subclinical hyperthyroidism, however, this relationship is mostly underappreciated as it may be partly due to the fact that the majority of the studies have not been associated with relevant clinical implications. There are an increasing number of populationbased studies in favor of hyperthyroidism as a risk factor for VTE. However, there is still a need for large-scale, prospective, multicenter studies to confirm it. Of course, finding a control group with overt hyperthyroidism who would serve as the control group for a prospective study for evaluation of VTE and/or bleeding occurrence is almost practically not feasible, and instead the general population may be recruited instead, however, this would not 


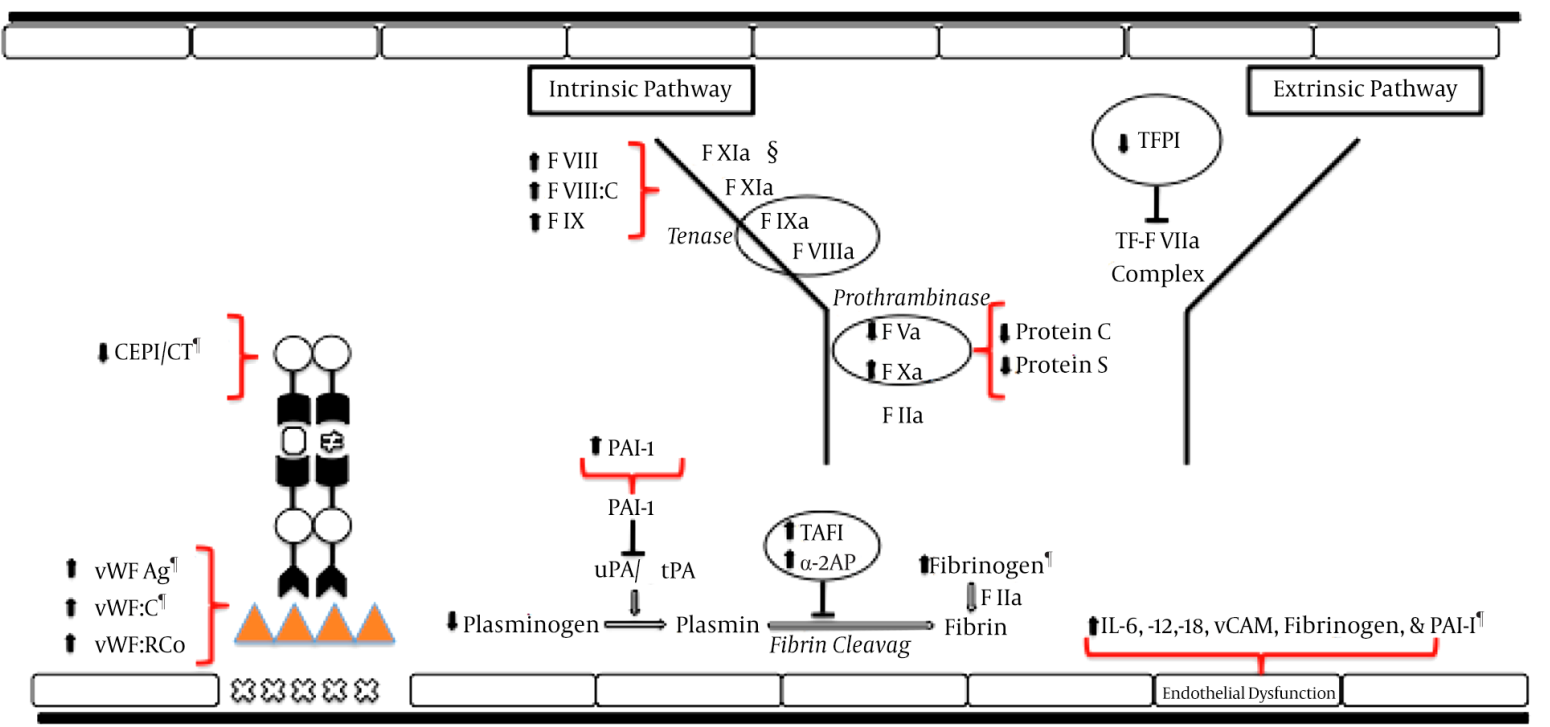

-Not all the mechanisms are shown here. For more details and their related references see text; $₫$ Mechanisms that contribute in both overt-and subclinical hyperthyroidism; §letter "a" as a suffix to each blood coagulation factor indicates its "activated" form (e.g., F XIIa is activaed F XII)

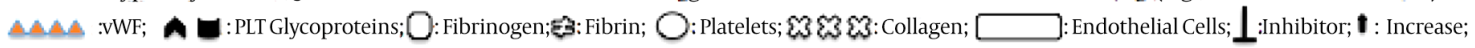

: Decrease

Abbrevitions: Ag, antigen; AIT, autoimmune thyroid disorders; F, coagulation factor; FVIII:C, FVIII activity; FVII:C, FVII activity; FVII activity; FVIIa, activated FVII; PAI-1, plasminogen activator inhibitor 1; PLT, platelets; SCH, subclinical hypothyroidism; tPA, tissue plasminogen activator; TF, tissue factor; Vwf, von Willebrand factor; vWF:C, vWF activity; uPA, Urokinase type plasminogen activator; $\alpha 2$ - $\mathrm{AP}=\alpha 2$.

be that much an issue with subclinical hyperthyroidism. The number of studies on subclinical hyperthyroidism is scarce though. Confirmation that overt-and/or subclinical hyperthyroidism would be a risk factor for VTE, and therefore a patient with VTE and hyperthyroidism can be classified as "provoked" or "unprovoked" has a significant impact on clinical management of the patients and the duration of anticoagulation therapy.

\section{Acknowledgments}

We are thankful to Mr. Fred King, medical librarian at Medstar Washington hospital center and Ms. RoseMarie Leone Winiewicz, director of Guha MD medical library at Providence Hospital for their technical assistance.

\section{Footnote}

\section{Conflict Of Interest: None to declare}

\section{References}

1. Furie B, Furie BC. Mechanisms of thrombus formation. $N$ Engl J Med. 2008;359(9):938-49. doi: 10.1056/NEJMra0801082. [PubMed: 18753650].
2. Furie B. Pathogenesis of thrombosis. Hematology Am Soc Hematol Educ Program. 2009:255-8. doi: 10.1182/asheducation-2009.1.255. [PubMed: 20008207].

3. Falati S, Gross P, Merrill-Skoloff G, Furie BC, Furie B. Real-time in vivo imaging of platelets, tissue factor and fibrin during arterial thrombus formation in the mouse. Nat Med. 2002;8(10):1175-81.

4. Arnout J, Hoylaerts MF, Lijnen HR. Haemostasis. Handb Exp Pharmacol. 2006(176 Pt 2):1-41. [PubMed: 17001771].

5. Fressinaud E, Baruch D, Girma JP, Sakariassen KS, Baumgartner HR, Meyer D. von Willebrand factor-mediated platelet adhesion to collagen involves platelet membrane glycoprotein IIb-IIIa as well as glycoprotein Ib. J Lab Clin Med. 1988;112(1):58-67. [PubMed: 2455762].

6. Foster PA, Fulcher CA, Marti T, Titani K, Zimmerman TS. A major factor VIII binding domain resides within the amino-terminal 272 amino acid residues of von Willebrand factor.J Biol Chem. 1987;262(18):84436. [PubMed: 3110147].

7. Stump DC, Mann KG. Mechanisms of thrombus formation and lysis. Ann Emerg Med. 1988;17(11):1138-47. [PubMed: 3142314].

8. Hulbert AJ. Thyroid hormones and their effects: a new perspective Biol Rev Camb Philos Soc. 2000;75(4):519-631. [PubMed: 11117200].

9. Vescovi PP, Favaloro EJ, Lippi G, Garofano M, Montagnana M, Manzato $\mathrm{F}$, et al. The spectrum of coagulation abnormalities in thyroid disorders. Semin Thromb Hemost. 2011;37(1):7-10. doi: 10.1055/s-00301270065. [PubMed: 21249600].

10. Erem C. Coagulation and fibrinolysis in thyroid dysfunction. En docrine. 2009;36(1):110-8. doi: 10.1007/s12020-009-9185-z. [PubMed: 19367377]. 
11. Shih CH, Chen SL, Yen CC, Huang YH, Chen CD, Lee YS, et al. Thyroid hormone receptor-dependent transcriptional regulation of fibrinogen and coagulation proteins. Endocrinology. 2004;145(6):2804-14. doi:10.1210/en.2003-1372. [PubMed: 14977860].

12. Doyle JB. Obstruction of the longitudinal sinus. Arch Neurol Psychiat 1927;29:374-82.

13. Squizzato A, Gerdes VE, Brandjes DP, Buller HR, Stam J. Thyroid diseases and cerebrovascular disease. Stroke. 2005;36(10):2302-10. doi: 10.1161/01.STR.0000181772.78492.07. [PubMed: 16179578].

14. Kaliebe $\mathrm{H}$. Autochthone sinusthrombose bei einem falle von morbus Basedow und tabes. Med Klinik. 1913;9:1929-32.

15. Marongiu F, Cauli C, Mariotti S. Thyroid, hemostasis and thrombosis. I Endocrinol Invest. 2004;27(11):1065-71. doi: 10.1007/BF03345311. [PubMed: 15754740].

16. Franchini M. Hemostasis and thyroid diseases revisited. J Endocrinol Invest. 2004;27(9):886-92. doi: 10.1007/BF03346287. [PubMed: 15648557].

17. Franchini M. Hemostatic changes in thyroid diseases: haemostasis and thrombosis. Hematology. 2006;11(3):203-8. doi: 10.1080/10245330600667591. [PubMed: 17325963].

18. Erem C, Ersoz HO, Karti SS, Ukinc K, Hacihasanoglu A, Deger O, et al Blood coagulation and fibrinolysis in patients with hyperthyroidism. J Endocrinol Invest. 2002;25(4):345-50. doi: 10.1007/BF03344016. [PubMed: 12030606].

19. Hofbauer LC, Heufelder AE. Coagulation disorders in thyroid diseases. Eur J Endocrinol. 1997;136(1):1-7. [PubMed: 9037116].

20. Ozcan MA, Comlekci A, Demirkan F, Yuksel F, Sari I, Demir T, et al. Plasma levels of free tissue factor pathway inhibitor in patients with various thyroid disorders. Thromb Res. 2003;110(4):243-7. [PubMed: 14512089].

21. Erem C, Kavgaci H, Ersoz HO, Hacihasanoglu A, Ukinc K, Karti SS, et al. Blood coagulation and fibrinolytic activity in hypothyroidism. Int J Clin Pract. 2003;57(2):78-81. [PubMed: 12661786].

22. Marongiu F, Conti M, Mameli G, Murtas ML, Balzano S, Sorano G, et al. Fibrinogen and fibrinolytic activity in hyperthyroidism before and after antithyroid treatment. I Endocrinol Invest. 1988;11(10):723-5. doi 10.1007/BF03350928. [PubMed: 2466071].

23. Marongiu F, Biondi G, Conti M, Murtas ML, Mameli G, Sorano GG, et al. Is a hypercoagulable state present in hypothyroidism? Thromb Haemost. 1992;67(6):729. [PubMed: 1509420]

24. Chadarevian R, Bruckert E, Leenhardt L, Giral P, Ankri A, Turpin G. Components of the fibrinolytic system are differently altered in moderate and severe hypothyroidism. J Clin Endocrinol Metab. 2001;86(2):732-7. doi: 10.1210/jcem.86.2.7221. [PubMed: 11158038]

25. Horne M3, Singh KK, Rosenfeld KG, Wesley R, Skarulis MC, Merryman $\mathrm{PK}$, et al. Is thyroid hormone suppression therapy prothrombotic? Clin Endocrinol Metab. 2004;89(9):4469-73. doi: 10.1210/jc.2004-0536. [PubMed: 15356049]

26. Hollowell JG, Staehling NW, Flanders WD, Hannon WH, Gunter EW, Spencer CA, et al. Serum TSH, T(4), and thyroid antibodies in the United States population (1988 to 1994): National Health and Nutrition Examination Survey (NHANES III). J Clin Endocrinol Metab. 2002;87(2):489-99. doi:10.1210/jcem.87.2.8182. [PubMed: 11836274].

27. De Schryver EL, Hoogenraad TU, Banga JD, Kappelle LJ. Thyrotoxicosis, protein C deficiency and lupus anticoagulant in a case of cerebral sinus thrombosis. Neth J Med. 1999;55(4):201-2. [PubMed: 10555439].

28. Molloy E, Cahill M, O'Hare JA. Cerebral venous sinus thrombosis precipitated by Graves' disease and Factor V Leiden mutation. Ir Med J. 2003;96(2):46-7. [PubMed: 12674153]

29. Mouton S, Nighoghossian N, Berruyer M, Derex L, Philippeau F, Cakmak $S$, et al. Hyperthyroidism and cerebral venous thrombosis. Eur Neurol. 2005;54(2):78-80. doi: 10.1159/000087717. [PubMed: 16118502]

30. Pekdemir M, Yilmaz S, Ersel M, Sarisoy HT. A rare cause of headache: cerebral venous sinus thrombosis due to hyperthyroidism. Am Emerg Med. 2008;26(3):383 e1-2. doi: 10.1016/j.ajem.2007.05.029. [PubMed: 18358972]
31. Siegert CE, Smelt AH, de Bruin TW. Superior sagittal sinus thrombosis and thyrotoxicosis. Possible association in two cases. Stroke. 1995;26(3):496-7. [PubMed: 7886732].

32. Squizzato A, Romualdi E, Buller HR, Gerdes VE. Clinical review: Thyroid dysfunction and effects on coagulation and fibrinolysis: a systematic review. J Clin Endocrinol Metab. 2007;92(7):2415-20. doi: 10.1210/jc.2007-0199. [PubMed: 17440013].

33. Farid NR, Griffiths BL, Collins JR, Marshall WH, Ingram DW. Blood coagulation and fibrinolysis in thyroid disease. Thromb Haemost. 1976;35(2):415-22. [PubMed: 989641].

34. Stuijver DJ, van Zaane B, Romualdi E, Brandjes DP, Gerdes VE, Squizzato A. The effect of hyperthyroidism on procoagulant, anticoagulant and fibrinolytic factors: a systematic review and metaanalysis. Thromb Haemost. 2012;108(6):1077-88. doi: 10.1160/TH12-070496. [PubMed: 23014708].

35. Parker JL, Lawson DH. Death from thyrotoxicosis. Lancet. 1973;2(7834):894-5. [PubMed: 4126930].

36. Predictors of thromboembolism in atrial fibrillation: I. Clinical features of patients at risk. The Stroke Prevention in Atrial Fibrillation Investigators. Ann Intern Med. 1992;116(1):1-5. [PubMed: 1727091].

37. Presti CF, Hart RG. Thyrotoxicosis, atrial fibrillation, and embolism, revisited. Am Heart J. 1989;117(4):976-7. [PubMed: 2929415].

38. van Zaane B, Stuijver DJ, Squizzato A, Gerdes VE. Arterial and venous thrombosis in endocrine diseases. Semin Thromb Hemost. 2013;39(5):489-95. doi:10.1055/s-0033-1343889. [PubMed: 23633192].

39. van Zaane B, Squizzato A, Huijgen R, van Zanten AP, Fliers E, Cannegieter SC, et al. Increasing levels of free thyroxine as a risk factor for a first venous thrombosis: a case-control study. Blood. 2010;115(22):4344-9. doi: 10.1182/blood-2009-11-253724. [PubMed: 20308594].

40. Elbers LP, van Zaane B, Gerdes VE, Coutinho JM, Bisschop PH, Fliers E. Venous thromboembolism in overt hyperthyroidism - a direct association with clinical implications? Neth J Med. 2014;72(4):242-4. [PubMed: 24829185].

41. Squizzato A, Vitale J, Gerdes VEA, Romualdi E, Büller HR, Ageno W. Recurrent deep venous thrombosis during optimal anticoagulation and overt hyperthyroidism: a case report. Blood Coagulation Fibrinolysis. 2007;18(8):801-3. doi:10.1097/MBC.0b013e3282fo9de2.

42. Verberne HJ, Fliers E, Prummel MF, Stam J, Brandjes DP, Wiersinga WM. Thyrotoxicosis as a predisposing factor for cerebral venous thrombosis. Thyroid. 2000;10(7):607-10. doi:10.1089/thy.2000.10.607. [PubMed: 10958314].

43. Danescu LG, Badshah A, Danescu SC, Janjua M, Marandici AM, Matta $\mathrm{F}$, et al. Venous thromboembolism in patients hospitalized with thyroid dysfunction. Clin Appl Thromb Hemost. 2009;15(6):676-80. doi: 10.1177/1076029609336856. [PubMed: 19671566].

44. Debeij J, Dekkers OM, Asvold BO, Christiansen SC, Naess IA, Hammerstrom J, et al. Increased levels of free thyroxine and risk of venous thrombosis in a large population-based prospective study. I Thromb Haemost. $\quad$ 2012;10(8):1539-46. doi: $10.1111 / j .1538-7836.2012 .04818 . x$. [PubMed: 22703181]

45. Lin HC, Yang LY, Kang JH. Increased risk of pulmonary embolism among patients with hyperthyroidism: a 5-year followup study. J Thromb Haemost. 2010;8(10):2176-81. doi: 10.1111/j.15387836.2010.03993.x. [PubMed: 20738759].

46. Debeij J, van Zaane B, Dekkers OM, Doggen CJ, Smit JW, van Zanten AP, et al. High levels of procoagulant factors mediate the association between free thyroxine and the risk of venous thrombosis: the MEGA study.J Thromb Haemost. 2014;12(6):839-46. doi:10.1111/jth.12573. [PubMed: 24679097].

47. Kootte RS, Stuijver DJ, Dekkers OM, van Zaane B, Fliers E, Cannegieter SC, et al. The incidence of venous thromboembolism in patients with overt hyperthyroidism: a retrospective multicentre cohort study. Thromb Haemost. 2012;107(3):417-22. doi: 10.1160/TH11-100691. [PubMed: 22234657]. 
48. Ramagopalan SV, Wotton CJ, Handel AE, Yeates D, Goldacre MJ. Risk of venous thromboembolism in people admitted to hospital with selected immune-mediated diseases: record-linkage study. BMC Med. 2011;9:1. doi: 10.1186/1741-7015-9-1. [PubMed: 21219637].

49. Franchini M, Montagnana M, Manzato F, Vescovi PP. Thyroid dysfunction and hemostasis: an issue still unresolved. Semin Thromb Hemost. 2009;35(3):288-94. doi: 10.1055/s-0029-1222607. [PubMed: 19452404].

50. Mohamed-Ali MS, Ahmed RO. Coagulation profiles in hypothyroid and hyperthyroid female patients in Sudan. Saudi Med J. 2008;29(9):1289-93. [PubMed: 18813414].

51. Myrup B, Bregengard C, Faber J. Primary haemostasis in thyroid disease. J Intern Med. 1995;238(1):59-63. [PubMed: 7541829].

52. Kurata Y, Nishioeda Y, Tsubakio T, Kitani T. Thrombocytopenia in Graves' disease: effect of T3 on platelet kinetics. Acta Haematol. 1980;63(4):185-90. [PubMed: 6771949].

53. Panzer S, Haubenstock A, Minar E. Platelets in hyperthyroidism: studies on platelet counts, mean platelet volume, 111-indium-labeled platelet kinetics, and platelet-associated immunoglobulins $\mathrm{G}$ and $\mathrm{M}$. J Clin Endocrinol Metab. 1990;70(2):491-6. doi: 10.1210/jcem-70-2-491. [PubMed: 2298861].

54. Dorr M, Robinson DM, Wallaschofski H, Schwahn C, John U, Felix SB, et al. Low serum thyrotropin is associated with high plasma fibrinogen. J Clin Endocrinol Metab. 2006;91(2):530-4. doi: 10.1210/jc.20051786. [PubMed: 16303831].

55. Lippi G, Franchini M, Targher G, Montagnana M, Salvagno GL, Guidi GC, et al. Hyperthyroidism is associated with shortened APTT and increased fibrinogen values in a general population of unselected outpatients. J Thromb Thrombolysis. 2009;28(3):362-5. doi: 10.1007/s11239008-0269-z. [PubMed: 18787930].

56. Bennett NB, Ogston CM, McAndrew GM. The thyroid and fibrinolysis. BrMed J. 1967;4(5572):147-8. [PubMed: 4168723].

57. Homoncik M, Gessl A, Ferlitsch A, Jilma B, Vierhapper H. Altered platelet plug formation in hyperthyroidism and hypothyroidism. $J$ Clin Endocrinol Metab. 2007;92(8):3006-12. doi: 10.1210/jc.2006-2644. [PubMed: 17488803].

58. Rogers J2, Shane SR, Jencks FS. Factor VIII activity and thyroid function. Ann Intern Med. 1982;97(5):713-6. [PubMed: 6814317].

59. Burggraaf J, Lalezari S, Emeis JJ, Vischer UM, de Meyer PH, Pijl $\mathrm{H}$, et al. Endothelial function in patients with hyperthyroidism before and after treatment with propranolol and thiamazol. Thyroid. 2001;11(2):153-60. doi: 10.1089/105072501300042820. [PubMed: 11288984].

60. Van Zaane B, Squizzato A, Debeij J, Dekkers OM, Meijers JC, Van Zanten $\mathrm{AP}$, et al. Alterations in coagulation and fibrinolysis after levothyroxine exposure in healthy volunteers: a controlled randomized crossover study. J Thromb Haemost. 2011;9(9):1816-24. doi:10.1111/j.15387836.2011.04430.x. [PubMed: 21729238].

61. Arnaout MA, Awidi AS, el-Najdawi AM, Khateeb MS, Ajlouni KM. Arginine-vasopressin and endothelium-associated proteins in thyroid disease. Acta Endocrinol (Copenh). 1992;126(5):399-403. [PubMed: 1621482].

62. Li Y, Chen H, Tan J, Wang X, Liang H, Sun X. Impaired release of tissue plasminogen activator from the endothelium in Graves' disease - indicator of endothelial dysfunction and reduced fibrinolytic capacity. Eur J Clin Invest. 1998;28(12):1050-4. [PubMed: 9893018].

63. Horacek J, Maly J, Svilias I, Smolej L, Cepkova J, Vizda J, et al. Prothrombotic changes due to an increase in thyroid hormone levels. Eur J Endocrinol. 2015;172(5):537-42.

64. Poplawska-Kita A, Siewko K, Telejko B, Modzelewska A, Mysliwiec J, Milewski R, et al. The changes in the endothelial function and haemostatic and inflammatory parameters in subclinical and overt hyperthyroidism. Int JEndocrinol. 2013:981638.

65. Hooper JM, Stuijver DJ, Orme SM, van Zaane B, Hess K, Gerdes VE, et al. Thyroid dysfunction and fibrin network structure: a mechanism for increased thrombotic risk in hyperthyroid individuals. J Clin Endocrinol Metab. 2012;97(5):1463-73. doi: 10.1210/jc.2011-2894. [PubMed:
22378816].

66. Klein I, Ojamaa K. Thyroid hormone and the cardiovascular system N Engl J Med. 2001;344(7):501-9. doi: 10.1056/NEJM200102153440707. [PubMed: 11172193].

67. Wahrenberg $\mathrm{H}$, Wennlund $\mathrm{A}$, Hoffstedt $\mathrm{J}$. Increased adipose tissue secretion of interleukin-6, but not of leptin, plasminogen activator inhibitor-1 or tumour necrosis factor alpha, in Graves' hyperthyroidism. Eur J Endocrinol. 2002;146(5):607-11. [PubMed: 11980614]

68. Morishita E, Hashimoto T, Asakura H, Saito M, Yamazaki M, Aoshima $\mathrm{K}$, et al. Increased plasma levels of free tissue factor pathway inhibitor in patients with Graves' disease. Thromb Haemost. 1998;79(5):919-23. [PubMed: 9609221].

69. Morikawa Y, Morikawa A, Makino I. Relationship of thyroid states and serum thrombomodulin (TM) levels in patients with Graves' disease: TM, a possible new marker of the peripheral activity of thyroid hormones. J Clin Endocrinol Metab. 1993;76(3):609-14. doi: 10.1210/jcem.76.3.7680353. [PubMed: 7680353].

70. Stuijver DJ, van Zaane B, Squizzato A, Meijers JC, Otten HM. The effects of an extremely high dose of levothyroxine on coagulation and fibrinolysis. J Thromb Haemost. 2010;8(6):1427-8. doi: 10.1111/j.15387836.2010.03854.x. [PubMed: 20345725].

71. Akinci B, Comlekci A, Yener S, Demir T, Ozcan MA, Bayraktar F, et al. Thrombin activatable fibrinolysis inhibitor antigen levels are inversely correlated with plasminogen activator inhibitor-1 antigen levels in hyperthyroid patients. Endocr J. 2007;54(4):593-9. [PubMed: 17690487].

72. Erem C, Ucuncu O, Yilmaz M, Kocak M, Nuhoglu I, Ersoz HO. Increased thrombin-activatable fibrinolysis inhibitor and decreased tissue factor pathway inhibitor in patients with hyperthyroidism. Endocrine. 2009;36(3):473-8. doi: 10.1007/s12020-009-9271-2. [PubMed: 19859836].

73. Stuijver DJ, Romualdi E, van Zaane B, Bax L, Buller HR, Gerdes VE, et al. Under-reporting of venous and arterial thrombotic events in randomized clinical trials: a meta-analysis. Intern Emerg Med 2015;10(2):219-46. doi: 10.1007/s11739-014-1168-2. [PubMed: 25502591].

74. Maraveyas A, Johnson M. Does clinical method mask significant VTE-related mortality and morbidity in malignant disease? $\mathrm{Br} J$ Cancer. 2009;100(12):1837-41. doi: 10.1038/sj.bjc.6605091. [PubMed: 19491905]

75. Sievert R, Goldstein ML, Surks MI. Graves' disease and autoimmune factor VIII deficiency. Thyroid. 1996;6(3):245-7. doi: 10.1089/thy.1996.6.245. [PubMed: 8837334].

76. Marongiu F, Cauli C, Mameli G, Usai B, Mariotti S. Apathetic Graves' disease and acquired hemophilia due to factor VIIIc antibody. J Endocrinol Invest. 2002;25(3):246-9. doi: 10.1007/BF03343998. [PubMed: 11936467].

77. Akinci B, Demir T, Comlekci A, Yener S, Ozcan MA, Karaoglu O, et al. Effect of levothyroxine suppression therapy on plasma thrombin activatable fibrinolysis inhibitor antigen levels in benign thyroid nodules. Med Princ Pract. 2011;20(1):23-8. doi: 10.1159/000322074. [PubMed: 21160209].

78. Loeliger EA, Van Der Esch B, Mattern MJ, Hemker HC. The Biological Disappearance Rate of Prothrombin, Factors Vii, Ix and X from Plasma in Hypothyroidism, Hyperthyroidism, and during Fever. Thromb Diath Haemorrh. 1964;10:267-77. [PubMed: 14113369].

79. Kellett HA, Sawers JS, Boulton FE, Cholerton S, Park BK, Toft AD. Problems of anticoagulation with warfarin in hyperthyroidism. Q J Med. 1986;58(225):43-51. [PubMed: 3704105].

80. Self T, Weisburst M, Wooten E, Straughn A, Oliver J. Warfarininduced hypoprothrombinemia. Potentiation by hyperthyroidism. JAMA. 1975;231(11):1165-6. [PubMed:1172818].

81. Collen D, Lijnen HR. Basic and clinical aspects of fibrinolysis and thrombolysis. Blood. 1991;78(12):3114-24. [PubMed: 1742478].

82. Rosc D. , Zastawna E. , Drewniak W. , Michalski A. , Kotschy M. . Plasminogen activators (tissue type t-PA, urokinase type u-PA) and plas- 
minogen activator inhibitor type 1 (PAI-1) in Graves disease. Med Sci Monit. 1998;4(6):975-8.

83. Maroney SA, Mast AE. New insights into the biology of tissue factor pathway inhibitor. J Thromb Haemost. 2015;13 Suppl 1:S200-7. doi: 10.1111/jth.12897. [PubMed: 26149025].

84. Simone JV, Abildgaard CF, Schulman I. Blood coagulation in thyroid dysfunction. N Engl J Med. 1965;273(20):1057-61. doi: 10.1056/NEJM196511112732001. [PubMed: 5834816].

85. Brona A, Bohdanowicz-Pawlak A, Jedrzejuk D, Milewicz A. Fibrinogen and D-dimers levels in patients with hyperthyroidism before and after radioiodine therapy. Endokrynol Pol. 2011;62(5):409-15. [PubMed: 22069101].

86. Erem C. Blood coagulation, fibrinolytic activity and lipid profile in subclinical thyroid disease: subclinical hyperthyroidism increases plasma factor X activity. Clin Endocrinol (Oxf). 2006;64(3):323-9. doi 10.1111/j.1365-2265.2006.02464.x. [PubMed: 16487444].

87. Gharib H, Tuttle RM, Baskin HJ, Fish LH, Singer PA, McDermott MT. Subclinical thyroid dysfunction: a joint statement on management from the American Association of Clinical Endocrinologists, the American Thyroid Association, and the Endocrine Society. J Clin Endocrino Metab. 2005;90(1):581-5. doi:10.1210/jc.2004-1231. [PubMed:15643019].

88. Biondi B, Palmieri EA, Fazio S, Cosco C, Nocera M, Sacca L, et al. Endogenous subclinical hyperthyroidism affects quality of life and cardiac morphology and function in young and middle-aged patients. J Clin Endocrinol Metab. 2000;85(12):4701-5. doi: 10.1210/jcem.85.12.7085. [PubMed: 11134131].

89. Iervasi G, Molinaro S, Landi P, Taddei MC, Galli E, Mariani F, et al Association between increased mortality and mild thyroid dysfunction in cardiac patients. Arch Intern Med. 2007;167(14):1526-32. doi: 10.1001/archinte.167.14.1526. [PubMed: 17646607].

90. Singh S, Duggal J, Molnar J, Maldonado F, Barsano CP, Arora R. Impact of subclinical thyroid disorders on coronary heart disease, cardiovascular and all-cause mortality: a meta-analysis. Int J Cardiol. 2008;125(1):41-8. doi:10.1016/j.ijcard.2007.02.027. [PubMed:17434631].

91. Cappola AR, Fried LP, Arnold AM, Danese MD, Kuller LH, Burke GL, et al. Thyroid status, cardiovascular risk, and mortality in older adults. JAMA. 2006;295(9):1033-41. doi: 10.1001/jama.295.9.1033. [PubMed: 16507804].

92. Walsh JP, Bremner AP, Bulsara MK, O'Leary P, Leedman PJ, Feddema $\mathrm{P}$, et al. Subclinical thyroid dysfunction as a risk factor for cardiovascular disease. Arch Intern Med. 2005;165(21):2467-72. doi:10.1001/archinte.165.21.2467. [PubMed: 16314542].

93. Gelfand RA, Hutchinson-Williams KA, Bonde AA, Castellino P, Sherwin RS. Catabolic effects of thyroid hormone excess: the contribution of adrenergic activity to hypermetabolism and protein breakdown. Metabolism. 1987;36(6):562-9. [PubMed: 2884552].

94. Coban E, Aydemir M, Yazicioglu G, Ozdogan M. Endothelial dysfunction in subjects with subclinical hyperthyroidism. J Endocrinol Invest. 2006;29(3):197-200. doi: 10.1007/BF03345539. [PubMed:16682830].

95. Gazdag A, Nagy EV, Burman KD, Paragh G, Jenei Z. Improved endothelial function and lipid profile compensate for impaired hemostatic and inflammatory status in iatrogenic chronic subclinical hyperthyroidism of thyroid cancer patients on L-t4 therapy. Exp Clin Endocrinol Diabetes. 2010;118(6):381-7. doi: 10.1055/s-0029-1224156. [PubMed: 19658059].

96. Coban E, Aydemir M. Levels of plasma fibrinogen and D-dimer in subjects with subclinical hyperthyroidism. Med Sci Monit. 2008;14(1):CR42-6. [PubMed: 18160944]. 